\title{
AFINAL, PARA QUE SERVE A ESCOLA?
}

\section{REPRESENTAÇÃO FEITA POR ADULTOS ALFABETIZADOS E ANALFABETOS.}

\author{
Leda Verdiani Tfouni* \\ Geraldo Romanelli* \\ Ana Maria Alvares** \\ Roberta M. da S. Gancia**
}

\section{RESUMO}

Este trabalho tem por objetivo investigar qual a opinião que grupos de adultos alfabetizados e nāo alfabetizados fazem da escola, bem como as suas representaçōes subjacentes acerca do papel social dessa instituição. Mais especificamente, procura-se verificar se a experiência concreta com a vida escolar, aliada à alfabetização, leva as pessoas a terem opiniōes sobre a éscola que seriam diferentes daquelas opiniōes de pessoas analfabetas, com pouca, ou nenhuma, experiência escolar.

\section{I - INTRODUÇÃO}

Em uma sociedade altamente letrada, que atingiu um alto grau de desenvolvimento tecnológico e científico, a condição dos analfabetos não somente os aliena do conhecimento produzido e sistematizado, impedindo-os de ter acesso a ele pela impossibilidade de ler e escrever, como tambem os aliena de si mesmos, por forçar a uma abdicação de suas próprias práticas culturais, o que ideologicamente acentua a marginalização. O mesmo argumento é válido para grupos alfabetizados com baixo grau de escolaridade, visto que, apesar de saberem ler e escrever, acabam ficando marginalizados devido a falta de qualificação, a qual está intimamente relacionada com a escola e o ensino especializado (Tfouni, 1987).

Sabe-se que o conhecimento valorizado pela sociedade circunscreve-se principalmente a esse conhecimento especializado oferecido pela escola, a qual, por conseguinte, é vista como um veículo que propicia a ascensão social. A literatura a respeito deste tema ilustra suficientemente essa discussão. Segundo alguns autores, não se pode entender a educação, que na realidade brasileira restringe-se principalmente ao âmbito escolar, sem considerar seus determinantes sociais, ou seja, deve-se compreendê-la através da análise de suas relações com as dimensões políticas, sociais e econômicas da sociedade. De acordo com Saviani (1982), a sociedade é marcada por uma acentuada divisão de

- Docentes do Departamento de Psicologia e Educação da Faculdade de Filosofia, Ciéncias e Letras de Ribeirăo Preto - U.S.P.

* Alunas da graduaçăo do curso de Psicologia do Departamento de Psicologia e Educaçăo da Faculdade de Fílosofia, Ciéncias e Letras de Ribeirăo Preto - U.S.P. 
classes, que se manifesta pelas "condições de produção de vida material" (op.cit. p.8) e as relaçōes sociais fundam-se, essencialmente, na base da força. Assim, de uma forma geral, a classe que possui mais força se apropriaria da produção material e do controle sobre a vida social, dominando a classe mais fraca, que se torna marginalizada.

O papel da escola, nesse contexto seria, então, o de reproduzir e reforçar a marginalidade social, já que esta seria inerente ao sistema no qual a escola está inserida. Conseqüientemente, os conhecimentos produzidos pela classe dominante, que são considerados como o saber legítimo, são apropriados por esta classe e dificilmente a parcela marginalizada da população tem acesso a esse corpo de conhecimento. $O$ conterudo que a escola transmite $\epsilon$ todo baseado em um conjunto de saber condizente com as necessidades da classe privilegiada e não com as da classe dominada, que nem sequer possui o mesmo vocabulário. No entanto, a classe dominante prega a superaçāo da marginalidade pela escola, através de discursos, como "oportunidades iquais para todos", alem de outros nos quais está embutida a idéia de ascensão social. Essas idéias veiculadas pela ideologia dominante não passam, porem, de ilusão, já que a escola reproduz as relaçöes sociais, mantendo o "status quo".

Assim, este segmento desprivilegiado da populaçāo, por ter necessidades prioritárias, como alimentaçäo, habitaçāo e saúde, acaba relegando a segundo plano a questāo da educaçāo, que nāo está ligada de forma tão direta ao problema da sobrevivência. Pode-se observar nestas camadas a inserção precoce dos individuos no mercado de trabalho. Por outro lado, contraditoriamente, exige-se, cada vez mais, um grau maior de escolaridade para o ingresso no mercado de trabalho, mesmo que determinadas funçōes não requeiram, necessariamente, esse saber escolar como mostra Spindel (1985, apud Madeira, 1986 ) a proposito da contratação de menores brasileiros. Vale ressaltar ainda que, muitas vezes, esse saber não garante o sucesso profissional. Desta forma, parece haver pouca relação entre a escolaridade, de um lado, e a renda $e$ a igualdade de oportunidades, do outro.

Apesar das dificuldades em assegurar a escolarizaçāo para os filhos, pesquisas como aquelas realizadas por Scarfon (1979), Lella (1987), Vieira e Mello (1987), entre tantos outros, mostram que grupos sociais marginalizados sonham com uma melhoria das condiçōes de vida, para si e para seus filhos, e relacionam-na com o estudo e a obtenção de um diploma.

Portanto, torna-se relevante analisar a maneira pela qual grupos de adultos analfabetos e alfabetizados (com baixo grau de escolaridade), que residem em um centro considerado altamente letrado e de alto desenvolvimentò tecnológico, como é o caso de Ribeirão Preto - S.P., representam a questão da escolarização e do sucesso profissional enquanto relacionada com o papel social da escola. 


\section{II - METOdologia E ANÁlise dOS DADOS}

A pesquisa foi realizada com 328 adultos residentes na região de Ribeirão Preto - S.P., divididos em oito grupos: "bóias- frias" alfabetizados; "bóias-frias" analfabetos; adultos alfabetizados que residem e trabalham na zona urbana; adultos analfabetos que residem e trabalham na zona urbana; adultos alfabetizados que residem na zona urbana e não trabalham; adultos analfabetos que residem na zona urbana e não trabalham; adultos alfabetizados que residem e trabalham na zona rural; e finalmente adultos analfabetos que residem e trabalham na zona rural. Vale notar que os alfabetizados tiveram seu grau de escolaridade controlado (no máximo até a $5^{2}$ série do $1^{2}$ grau completa ). Por outro lado, alguns analfabetos tiveram experiência com o ensino formal, havendo freqüentado a escola, em alguns casos, por ate 7 anos (isto, no entanto, não foi suficiente para garantir-lhes a aprendizagem mínima possibilitada pela escola, que é aprender a ler e a escrever).

Comparando os dois grupos, alfabetizados e analfabetos, pode-se dizer que eles diferem entre si não somente com relação à alfabetização, como também quanto a: grau de escolaridade, tempo de escolarizaçăo, experiência com o ensino formal, e distribuiçāo quanto ao sexo. Assemelham-se, no entanto, no fato de serem marginalizados das profissōes mais especializadas que, dentro do mercado de trabalho, são exercidas por aqueles que possuem pelo menos instrução de nível superior.

Os dados a respeito da representação sobre a escola foram colhidos através da pergunta "Para que serve a escola?". As respostas dadas pelos adultos foram gravadas, transcritas, e submetidas a um processo de categorização, baseado em uma análise do conteúdo das mesmas. A Tabela 1 mostra o resultado desta análise.

Nota-se, inicialmente, examinando a Tabela 1, que a representação da escola subjacente às. categorias de 1 a 6 é predominantemente positiva, enquanto que a categoria 7 agrupa aquelas opiniōes que denotam uma representação negativa da escola por estes adultos.

A categoria 1, "A escola vista como propiciadora de melhores condiçōes futuras" contém a idéia de que o fato de freqüentar a escola por si só pode proporcionar às pessoas melhores condições de vida, principalmente no que diz respeito à situação econômica. Nota-se que essa representação da escola é a mais frequiente, tanto para os alfabetizados quanto para os analfabetos, havendo um percentual maior entre os analfabetos (37,3\% contra $34.5 \%)$.

Em segundo lugar vem a categoria "A escola vista como fonte onde o indivíduo busca conhecimento", que contém a idéia de que na escola se pode aprender, de maneira ativa, desde ler, escrever, e fazer contas, até como orientar os filhos. Constata-se que os percentuais são quase iguais para os dois grupos. 
TABELA 1 - Representação da escola: Comparação entre adultos alfabetizados e não-alfabetizados a partir das categorias obtidas para os dois grupos.

\begin{tabular}{|c|c|c|}
\hline CATEGORIAS & ANAIR. & Ald. \\
\hline $\begin{array}{l}\text { 1. A escola vista como propiciadora de melhores condiçoes } \\
\text { futuras }\end{array}$ & (78) 37.3 & (90) 34.5 \\
\hline $\begin{array}{l}\text { 2. A escola vista como fonte onde o individuo busca conheci- } \\
\text { mento }\end{array}$ & (54) 25.8 & (69) 26.5 \\
\hline $\begin{array}{l}\text { 3. A escola vista como um ambiente socializador que propi- } \\
\text { cia o desenvolvimento individual e social }\end{array}$ & (35) 16.7 & (38) 14.6 \\
\hline $\begin{array}{l}\text { 4. A escola vista como detentora exclusiva do conhecimen- } \\
\text { to e responsável por sua transmissto }\end{array}$ & (19) 9.1 & (30) 11.5 \\
\hline $\begin{array}{l}\text { 5. A escola vista como propiciadora da obtengato de um sta- } \\
\text { tus social mais clevado }\end{array}$ & - & (11) 4.3 \\
\hline $\begin{array}{l}\text { 6. A escola vista como propulsora do desenvolvimento tec- } \\
\text { nológico }\end{array}$ & (01) 0.5 & (07) 2.8 \\
\hline $\begin{array}{l}\text { 7. A escola vista como algo que nato faz parte da realidade } \\
\text { dos indivíuos estudados }\end{array}$ & (04) 1.9 & (11) 4.2 \\
\hline 8. Imprecisas & (17) 8.1 & (04) 1.5 \\
\hline 9. Sem respostas & (01) 0.5 & \\
\hline TOTAL & $(209) 100$ & (261) 99.9 \\
\hline
\end{tabular}

OBSERVAÇĀO: O tolal de calegortas (470) excede o lolal de adultos porque uma finica resposta poderia ser desdobrada em mais de uma calegoria.

"A escola vista como um ambiente socializador que propicia o desenvolvimento individual e social" é a categoria que aparece em terceiro lugar, e exprime a idéia de que a escola não transmite apenas o conhecimento formal, mas serve também para que as pessoas sintam-se mais adaptadas ao seu ambiente social, pöendo, assim, desenvolver-se individualmente atraves da facilitação para estabelecer contatos sociais . Aqui tamberm não existe diferença entre os adultos alfabetizados e os analfabetos.

"A escola vista como detentora exclusiva do conhecimento e responsável por sua transmissão" é uma categoria que expressa o modo pelo qual os adultos parecem representar-se como agentes passivos no processo ensino-aprendizagem, ao mesmo tempo em que atribuem à escola o papel de transmissora de conhecimentos que ela detém de forma absoluta. Vemos aí um percentual maior para os adultos alfabetizados (11.5\%) do que para os analfabetos $(9,1 \%)$.

A categoria 5, "A escola vista como propiciadora de obtenção de um status social mais elevado" ocorre apenas em $11.5 \%$ dos alfabetizados, e revela a representação de que ir à escola significa uma valorização do indivíduo em termos culturais e sociais, indo, portanto, além da expectativa de melhoria das condições econômicas, como o caso da categoria 1. 
Finalmente, temos que apenas um adulto analfabeto representa a escola como propulsora do desenvolvimento tecnológico, o que denota uma visão mais abrangente do papel da escola, voltada para o progresso social como um todo.

Por fim, a categoria 7 agrupa as representaçōes denominadas "negativas" . Revelam uma representaçăo desfavorável sobre o papel da escola, tanto do ponto de vista individual ("A escola por si so nāo garante um bom emprego") quanto do ponto de vista social mais amplo ("A escola não ensinà a viver; o mundo e que ensina"). A porcentagem do grupo alfabetizado $(2.8 \%)$ e maior do que a do grupo analfabeto (1.9\%).

\section{III - DISCUSSAO}

Atraves dos dados obtidos podemos constatar que ambos os grupos estudados atribuem um alto valor a escola, ja que grande parte das categorias relacionam a freqüência à escola e os conhecimentos nela adquiridos com idéias de ascensão social, desenvolvimento individual e social, entre outras.

$O$ ideal da doutrina liberal de escola para todos e de garantia de mobilidade social através da escolarizaçāo, sabe-se bem, não funciona em sociedades como a nossa. No entanto, os adultos pesquisados, tanto alfabetizados e com alguma escolaridade, quanto os analfabetos, parecem representar a instituição escolar de maneira idealizada, de acordo com a forma como ela é representada no discurso oficial.

Assim, nas categorias de 1 a 5 , na Tabela 1 , vemos a escola representada como a única instituição capaz de criar condiçōes mais satisfatórias, tanto no trabalho, quanto nas relaçōes sociais. Esses conteúdos expressam ainda o desejo desses adultos de adquirir conhecimento, o que parece indicar que atribuem um valor positivo à posse do saber sistematizado e "oficial" transmitido pela escola, saber esse que, para eles funcionaria como facilitador da participação e convivência em outros ambientes sociais, além de ter o poder de amenizar aspectos desagradáveis e ásperos do cotidiano. Essa aspiração simbólica, que tem a função de amenizar esse cotidiano sofrido, ligada ao ideal de "ter cultura", e "ter diploma", está presente nos dois grupos de adultos estudados, mas parece expressar-se de forma mais elaborada no grupo alfabetizado, e de maneira mais difusa nos analfabetos. Temos aí um efeito da maior vivência e da experiência concreta com a escola, o que evidencia a existência do chamado "currículo oculto", que passa, ao lado dos conteudos explícitos (programáticos) toda uma ideologia auto-promocional, que tem a função de ocultar que é exigido, no processo de escolarização, um saber prévio do qual esses adultos são destituídos, o que impossibilita a continuação do processo, gerando o fracasso escolar. Como consequiência, o individuo acaba atribuindo a si próprio a culpa pelo fracasso.

Por outro lado, a ocorrência das categorias "negativas" parece conter uma representação que revela uma atitude mais realista para lidar com a 
frustração frente ao fracasso. Com efeito, sabe-se que atualmente existe uma super valorização da escola, que está ligada à exigência cada vez mais acentuada de um maior grau de escolaridade para o ingresso no mercado de trabalho, mesmo que determinadas funçōes não requeiram necessariamente 0 saber escolar (Braverman, 1977). Muitas vezes, ainda, esse saber näo garante o sucesso profissional. Lella (1987) mostra, através de pesquisa realizada com adultos analfabetos, que existe também no Brasil uma exigência cada vez maior de qualificação (e escolaridade) para ocupaçōes similares. Assim, alguns dos adultos estudados colocam a instituiçäo escolar como algo fora, quer da sua realidade, quer de suas necessidades, quer de suas expectativas, o que equivale a nảo aceitar o sonho para si, sem que isso os impeça de continuar sonhando um futuro melhor para seus fillhos: "boa para os pequenos, porque para 0 adulto nāo serve mais ...". (CNPq, FAPESP, Fundo de Pesquisa - USP).

\section{Y - REFERENCIAS BIBUOGRAFICAS}

Braverman, H. "Nota final sobre qualificação" in: Braverman, H. Trabalho e Capital Monopolista. Zahar: Rio de Janeiro, 1977.

Lella, C. de "Os livros-texto do primário intensivo para adultos: principais interesses e opiniōes de seus usuários". Cadernos de Pesquisa, 61, 30-41, 1987.

Madeira, F. R. "Los jovenes en el Brasil: antigos supuestos y nuevos derroteros." Revista de la CEPAL, Santiago, no 29, 57-80, ago. 1986.

Saviani, D. "As teorias da educação e o problema da marginalidade na América Latina." Cadernos de Pesquisa, 42, 8-18, 1982.

Scarfon, M. de L. Crescimento e Miséria . Símbolo: São Paulo, 1979.

Spindel, Cheywa R. "O menor assalariado registrado: condiçōes de trabalho em áreas metropolitanas. Textos IDESP, São Paulo, n² 8, 1985.

Tfouni, L. V. "A inteligência prática e a prática da inteligência". Arquivos Brasileiros de Psicologia, 39 (3), 44-56. 1987.

Vieira, L. M. F. e Melo, R. L. C. de "A creche comunitária Casinha da Vovo: prática de manutenção/prática de educação". Cadernos de pesquisa, 62, 60-78, 1987.

\section{ABSTRACT}

The aim of this paper is to investigate adult illiterate and semi-literate's opinion about school, as well as their underlying representations about the social role of that institution. More especifically, we try to determine whether people's concrete schoolling experience, together with literacy, drive them to have opinions about school which would show to be different from illiterate, or semi- literate adults. 